\title{
Helicobacter pylori: its discovery and relevance for medicine
}

\author{
J. M. Pajares and J. P. Gisbert \\ Service of Gastroenterology. University Hospital La Princesa. Universidad Autónoma. Madrid, Spain
}

\begin{abstract}
In 1979, Warren was first to observe these bacteria in an inflamed gastric epithelium, and subsequently in peptic ulcer-associated gastritis. In 1981, Marshall starts his research and cultivates the bacteria, performs prospective studies, and administers therapy regimens using antibiotics and bismuth salts. The organism was designated Campylobacter-like after its similarity with said genus. In 1984, Marshall manages to meet Koch's postulates using selfinoculation by ingesting a bacterial culture, which resulted in gastritis that was then treated and cured with bismuth salts and metronidazole. The Gastroenterological Society of Australia rejected the abstract with preliminary data. In 1983, "The Lancet" published such data in two brief letters with the same heading, with each being signed by one of these two researchers. Cooperating with microbiologists they classify the new bacteria within the Helicobacter genus as the pylori species. Gastritis and peptic ulcer are currently considered infectious diseases. Their diagnosis and therapy include bacterial detection methods and antibiotics, respectively. In addition, a causal relationship between Helicobacter pylori and both gastric adenocarcinoma and gastric lymphoma has been established, and its association with some extradigestive conditions has been suggested.
\end{abstract}

Key words: Helicobacter pylori. Discovery. Nobel 2005. Peptic ulcer. Duodenal ulcer. Gastric ulcer. Gastritis.

Pajares JM, Gisbert JP. Helicobacter pylori: its discovery and relevance for medicine. Rev Esp Enferm Dig 2006; 98: 770785.

Recibido: 26-04-06.

Aceptado: 09-05-06.

Correspondencia: José María Pajares-García. Servicio de Aparato Digestivo. Hospital de La Princesa. Diego de León, 62. 28006 Madrid. e-mail: jpajaresg@medynet.com

\section{INTRODUCTION}

In November 2005, Robin Warren and Barry Marshall were awarded the Nobel Prize in Physiology or ( $i . . . ?)$ Medicine. The Board members summarized their contribution to science with these words: "extraordinary and unexpected discovery that gastric inflammation (gastritis), as well as stomach and duodenal ulcer (peptic ulcer disease), result from a gastric infection by the bacterium Helicobacter pylori" (1).

\section{HOW WAS THIS DISCOVERED?}

While independently, both prize-winning investigators complemented their research. Warren was first to see the organism on June 11, 1979 -his $42^{\text {nd }}$ birthday. He comments on his finding as follows: "I was doing my daily chore of examining preparations for the microscopic study of gastric biopsies. In a preparation of gastric mucosa with active chronic gastritis, I saw a blue line on the surface of the gastric epithelium. Using greater magnification I clearly saw that many small bacilli made up the blue line, and were strongly adherent to the epithelium's surface. I confirmed my suspicion using an immersion lens".

During the following 18 months, Warren studied and collected more samples where gastritis-related histological lesions were always associated with these bacteria. Being a pathologist he was clear that bacteria present in any inflamed tissue should be considered causal agents. However, he had to fight the dogma that bacteria just do not grow in the stomach's acid medium (2). Nobody believed in him but his wife Win, a psychiatrist who enthusiastically encouraged him. This Warren acknowledged in an interview with these words: "I look up to my wife, and am grateful for her moral help; having to raise five children, she was all the more right to be upset -her hus- 
band had wasted time and money searching for non-existent bacteria; however, she listened and encouraged him when he was back home, sometimes at daybreak" (3). Now, when thinking back to those days, he believes her wife had all reasons to make him visit, as a patient, one of her psychiatrist colleagues (2).

Warren had a logical mind and was an expert in histological staining. To identify the components of the aforementioned "blue line" he tried the Gram and WarthinStarry stains (with silver preparations). Using both stains -particularly the latter- he managed to dye and tell apart bacteria from epithelial cells. He also examined thinner mucosal sections under an electron microscope, and saw the bacteria firmly adhering to the epithelium's surface. Len Matz, a pathologist in the same department, also saw it and told him: "if you really think this is a relevant finding, keep on searching in more patients" (2).

Warren continued his search for bacteria in all histological preparations from gastric mucosa, and indeed found their presence in active chronic gastritis samples. They often showed up in small foci. To be even more sure he showed the images obtained with an electron microscope to experts in this imaging technique, who confirmed the presence of bacteria from their similarity to those previously reported by Fung et al. in 1979 (4). To rule out the possibility that the organisms seen were in fact commensal rather than pathogenic bacteria he looked at 20 cases where gastric histology was normal, with no inflammatory cells and no bacteria.

Warren searched alone until 1981. On this year he was visited by Barry Marshall, a 31-year-old participant in the Royal Australian College of Physicians' clinical specialization program. To meet his program goals Marshall had to complete a research project. He initially rejected the subject suggested by his boss, because he considered it irrelevant; his boss replied: "If you want something interesting, you'll likely find it in the Pathology Department; you better go see that "crazy" Warren, who's trying to turn gastritis into an infectious disease" (5).

During their first interview (Fig. 1), while not very convinced, he accepted the commitment to collect biopsy samples from 20 patients with an absolutely normal gastric mucosa on endoscopy. He was satisfied to see that no bacteria were present in the non-inflamed gastric mucosa. From this observation on he became increasingly enthusiastic for the project, to which he devoted all his intelligence, his will, and both his work and leisure time.

Marshall cooperated with microbiologists to find an appropriate culture technique for the "new bacteria". From its similarity with Campylobacter they selected the medium and incubation times that were standard for said genus. Early attempts using this method failed. However, fortune helped these tenacious researchers. On their return from vacation a lab technician realized that the culture plate for biopsy 35 had not been removed from the heater. On attentive observation, he saw the presence of minute clear colonies. He identi-

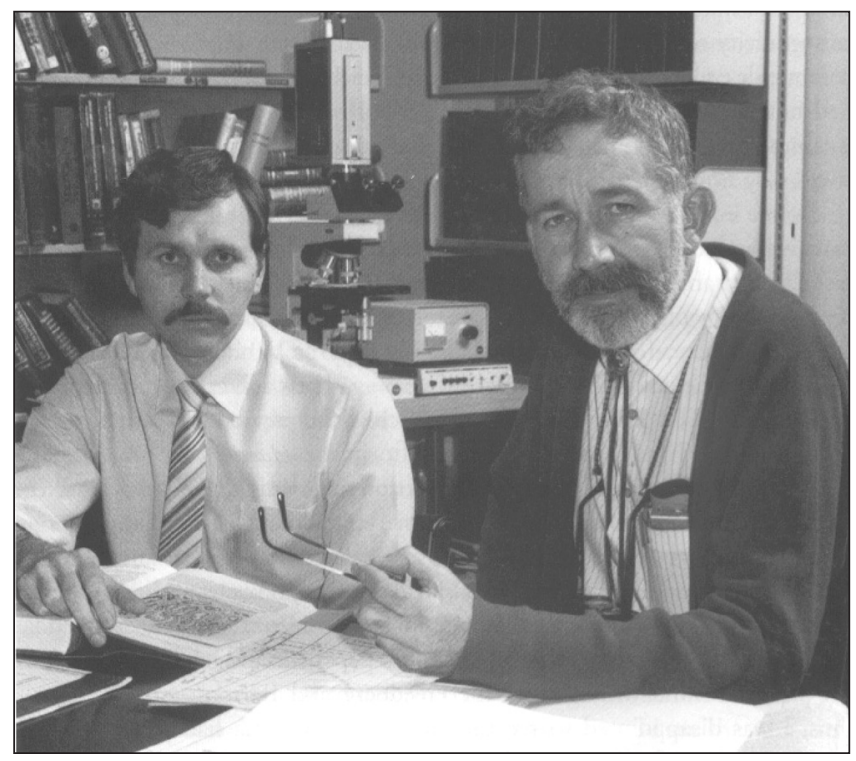

Fig. 1.- A picture showing Warren and Marshall taken in July 1984 (taken from reference 8 , with permission).

Fotografía de Warren y Marshall realizada en julio de 1984 (tomada de referencia 8, con permiso de los autores).

fied these bacteria, which were similar to those seen in histological preparations.

\section{THE SEARCH FOR DRUGS TO TREAT INFECTION}

In October 1981, still with no bacterial cultures available, they treated their first patient, an elderly male of Russian descent with severe gastritis whose biopsy showed countless Campylobacter-like organisms. They initiated treatment with tetracycline for 14 days based on previous knowledge that Campylobacter is susceptible to this antibiotic agent. They knew they were verging on ethical limits, and that the result obtained was merely anecdotal and lacking scientific value. Having shared these considerations with their patient, as well as their concerns regarding response, he finally accepted. Following treatment onset both abdominal pain and nausea subsided. While they still saw an erythematous gastric mucosa on their follow-up endoscopy, acute inflammation features had improved and the bacteria had disappeared.

Encouraged by this favorable outcome they planned a therapy trial for infected patients with duodenal (DU) or gastric ulcer (GU). How were they to fund this trial? What drugs were to be selected? These and many other concerns did not discourage Marshall despite his being a 31-year-old young man, an unknown stranger from a distant city across the world. He contacted several pharmaceutical companies with little success. Gist-Brocades, a Dutch company that had synthesized bismuth salt (col- 
loidal bismuth subcitrate), answered Marshall's call for help, and sent him a number of papers on the drug that revealed a smaller number of relapses in patients with peptic ulcer (PU) who had been treated with said bismuth salt versus those who had received cimetidine (6), as well as bacterial eradication in those with bismuth salt (7). Inspired by these data, Marshall included bismuth salt (Denol) and cimetidine plates in Campylobacter pylori cultures, and saw "bacterial inhibition areas" around bismuth but not cimetidine plates.

With few though scientifically-grounded data Marshall designed a prospective clinical trial where patients were included in two arms: in one arm, patients received Denol (suspension formulation); in the other arm, patients received cimetidine (Tagamet). No double-blind condition could be established, as no other researcher contributed work. Few patients accepted -only 15 in each group. Results were unsatisfactory, as relapse rates were identical in both groups. However, upon the histopathologic study of biopsies obtained both before and after therapy, he found that gastritis had decreased in those receiving the bismuth salt. He also found that most patients had discontinued bismuth because of poor taste (5).

Despite these results, he continued with their protocol. They treated with Denol, the new chewable tablet presentation, a patient with relapsing ulcer. As a result of treatment the patient developed periodontitis, which was cured with metronidazole. At follow-up endoscopy, the DU was healed and the bacteria were no longer present. A coincidence or a synergistic effect of bismuth plus metronidazole? Marshall answered by checking the bacterium's susceptibility to metronidazole in 9 of 10 cultures. He added this antibiotic to Denol in a new dual therapy, using which he cures (eradicates) infection in 8 of 10 treated patients. During 1984, he tried dual regimens using bismuth salts plus amoxicillin or tetracycline, which were relatively effective even if bismuth in association with metronidazole yields poorer results (5).

In 1984, both investigators submit a full paper with all their data to The Lancet. Again, the editors are reluctant to accept it, since reviewers having assessed the article considered it insufficiently relevant for publication. The authors suggest other reviewers, who finally approve it. The editors add a praiseworthy note to highlight the discovery's originality and importance (8). Several letters referring to the new bacteria were published in that same issue: MacNulty and Watson from Skirrow's lab reported the finding of spiral bacteria in the gastric antrum (9); Langerberg et al., from Amsterdam, reported the presence of urease in these bacteria (10); and Eldridge et al. mentioned the detection of antiCampylobacter antibodies in infected patients (11).

\section{MEETING KOCH'S POSTULATES}

In January 1984, Marshall and Stuart Goodwin, a microbiologist at the Experimental Microbiology Department, agreed to inoculate pigs -the animal they considered most fit- with pure Campylobacter cultures. These experiments failed. Marshall was not discouraged, however. He decided to inoculate himself, and informs his boss Ian Hislop and his friendy, the pathologist David MacGechie, who tried to dissuade him by discussing a number of scientific and ethical issues. He ignored their advice and kept his decision. His behavior was neither irresponsible nor heroic. As he himself has stated on several occasions, he was exposing himself to an infection for which he knew there was a cure.

In June 1984, he fasted and visited the Endoscopy Unit half an hour before opening time. He asked his boss to start with him, as he wanted to establish whether his gastric mucosa was normal and gastritis-free. Gastric biopsy was normal. In that same endoscopy session biopsies are obtained from an adult male with dyspeptic symptoms. His gastric biopsy revealed the presence of gastritis. Abundant metronidazole-susceptible Campylobacter organisms grew in his culture. Dual therapy with bismuth salts and metronidazole cured the patient's infection. A second follow-up endoscopy established that gastritis had been cured.

Marshall had followed this patient with increasing interest. Upon learning that gastritis had been cured he decided to select this patient's gastric biopsy cultures for his own inoculation. He took $30 \mathrm{~mL}$ from this culture aside, which he ingested following $400 \mathrm{mg}$ of cimetidine in an attempt to reduce acid secretion and thus facilitate gastric infection (5).

For the first six days, Marshall experienced no symptoms. On the $7^{\text {th }}$ day he woke up with severe nausea and vomiting, which stayed for three additional days. The vomited material was of a light color and had no acid taste. On the tenth day, he underwent his second endoscopy, which was performed at closing time given the high number of visiting patients. Despite the fact that he was apathetic and physically weak he did not remain inactive, for he prescribed therapies for infected patients all morning. His second endoscopy was much more uncomfortable than the previous one. The biopsy revealed gastritis, and Campylobacter grew in the related culture. That day he told his wife that he had inoculated himself with a bacterial culture. She looked angrily at him, and showed him his four children. Marshall made it all up when he reminded her -using his usual sense of humor- that most members of the scientific community were pretty sure that the inoculated germs were no pathogens at all. He started therapy with bismuth salts and metronidazole for 14 days, and his complaints disappeared. In his third endoscopy, at one month after treatment completion, histology had returned to normal, and bacteria had disappeared (12).

\section{REPORTING OF RESULTS TO THE SCIENTIFIC COMMUNITY}

In October 1982, Marshall presented his initial data, which were severely criticized, at the local College of Physicians meeting. A major objection raised was related 
to the association between DU and gastritis, as the scientific community related gastritis only to GU. To counter this argument Marshall reviewed the literature and found a paper from 1950 documenting that $100 \%$ of patients with DU had antral gastritis (5).

Together with Warren he decided to report their collected data to their Canadian gastroenterologist colleagues. In February 1983, they submitted an abstract to the Gastroenterological Society of Australia, which was not accepted. In their answering letter the scientific committee justified their rejection quoting their difficulties to accept 56 of all 67 papers received. Their paper lacked scientific interest.

Their refusal did not discourage these investigators. They contacted the English microbiologist Martín Skirrow, a Campylobacter expert, who revised their data and repeated their cultures using his own patients, with the same results. Having become an ally, he managed to have the abstract accepted at a Campylobacter Workshop to be held by microbiologists that same year in Brussels. Skirrow cooperated in the search for a new name for the novel bacterium at a meal organized to honor Marshall, to which he had invited a prestigious dermatologist who had first identified Campylobacter laridis in the gull. Following a relaxed talk they agreed on Campylobacter (after similarities with said bacterium) and the adjective "pylori" or "pyloridis", after the germ's primary localization at the pyloric area (5).

During the aforementioned Workshop, data reported drew the attention of prestigious microbiologists who were interested in Campylobacter, who hence expanded their research lines to include Campylobacter pylori. Marshall also managed to interest a fair number of gastroenterologists and pathologists in the research on these bacteria.

In 1983, Warren and Marshall made their findings known to the scientific world in two brief letters separately submitted to the Editor of the prestigious journal "The Lancet". David Fox, the journal's assistant editor, was perplexed by his reception of two letters by different authors with the same heading. He contacted both to learn their reasons. Warren argued that he had been first to see these bacteria, and hence he claimed his right to be considered the original discoverer. Marshall, in turn, claimed his priority in authorship from the fact that he had coordinated and encouraged cultures, a clinical trial, and contact with other microbiologists, etc. All reasons considered, the Editor accepted both letters to be published with the same heading -"Unidentified curved bacilli on gastric epithelium in active chronic gastritis"- on June 4, $1983(13,14)$, with these references having been subsequently quoted thousands of times in all type of medical journals.

\section{DEFINITIVE CLASSIFICATION OF THE BACTERIUM WITHIN THE GENUS HELICOBACTER}

The new bacteria had been provisionally included within the Campylobacter genus. With members in this genus, the new germ shared a spiral shape, its microaerophilic capabilitis, potential growth in the same culture medium, and other biochemical characteristics. However, it differed in two major features: the presence of multiple flagella on one end, and a high urease contents. The analysis of several spiral bacteria among Campylobacter and other species using electron microscopy revealed that Campylobacter pylori was more similar to Aquaspirillum, a member of the genus Spiril$\operatorname{lum}(15)$.

Another team of investigators, applying the measurement of percentage guanine and cytosine content in bacterial DNA, which had been used for the taxonomic classification of other species, analyzed and compared the content of such nitrogen bases in Campylobacter pylori and bacteria belonging to the genus Helicobacter, which had been recently discovered by Australian microbiologists in the roe deer (16). The proportion of guanine and cytosine -35-38\% - found in Campylobacter pylori was more akin to that of the Helicobacter genus (17).

Investigation continued with the use of molecular biology techniques to sequence $16 \mathrm{~S}$ ribosomal RNA in Campylobacter pylori, and the information obtained was compared to that collected from other bacteria; also with the measurement of fatty acid content using gas-fluid chromatography, which had previously helped establish a definitive taxonomy for numerous members in the Campylobacter family: jejuni, coli, laridis, etc. (18-20).

Finally, by pooling together fatty acid content data as obtained with gas-fluid chromatography, and information from DNA-DNA hibridation, and then comparing them to those obtained from other bacteria, a group of microbiologists led by Goodwin demonstrated that Campylobacter pylori was in fact a distinct member not belonging in the Campylobacter genus, but had morphological, and structural biochemical characteristics more akin to those seen in the new Helicobacter genus. In 1989, based on the existing scientific data, they published a paper discussing the facts that warranted the name change from Campylobacter to Helicobacter pylori (21). This name has been recognized and accepted by the scientific community worldwide ever since.

\section{RELEVANCE OF THE DISCOVERY OF HELICOBACTER PYLORI IN MEDICINE}

The discovery of these bacteria has involved deep conceptual changes in the understanding of gastroduodenal disease. To a lesser extent, also in the understanding of some extradigestive conditions. Thus, a new etiopathogenicity was considered for gastritis and PU. Indeed, the development of gastritis in Marshall's stomach cleared up any doubts on the pathogenetic capabilities of Helicobacter pylori to give rise to this lesion. The experiment complied with requirements as demanded by Koch. Subsequently a number of papers were published with data on 
the prevalence of Helicobacter pylori in gastritis, which approached $80 \%$ in the multifocal form -the form associated with GU- and $100 \%$ for antral or type-B gastritis -the form associated with DU $(22,23)$.

How could the causal mechanism of Helicobacter pylori resulting in PU be explained? It was not an easy task. Two pieces of data supported this hypothesis: one was epidemiological, the other clinical in nature. The former had been conclusive, since studies worlwide demonstrated an association between Helicobacter pylori and DU in almost $100 \%$ of patients, as well as in 80 to $95 \%$ for GU.

On the other hand, the repeatedly established fact that PU healed in patients receiving antisecretory agents, but relapsed in most cases after 12 months was really eyecatching. However, there was no PU relapse when antibiotics were added and the infection was cured (24). This same result was obtained when Helicobacter pylori infection was cured with antibiotic therapy alone, with no concomitant antisecretory agents (25).

Regarding his acute infection, Marshall had induced himself a gastritis, not a PU. The paradigmatic association of a high gastric acidity with DU was still in force for infected patients with PU. What is the role of $\mathrm{pH}$ (gastric acidity) and that of Helicobacter pylori infection? How can both agents become integrated?

Several duodenal mucosa studies in patients with ulcer revealed the presence of gastric mucosa at the bulb or gastric metaplasia, mucosal inflammation or duodenitis, and the presence of Helicobacter pylori at the metaplastic mucosa inside the duodenum (26). The chronic inflammatory response of the gastroduodenal mucosa generates inflammation mediators and a reduction in somatostatin, which brings about hypergastrinemia $(27,28)$. A feasible hypothesis on the pathogenesis of DU integrated gastric hypersecretion as the cause of gastric metaplasia at the duodenal cup and Helicobacter pylori infection together. Thus, these bacteria migrated to the duodenum and there they colonized and inflamed bulbar mucosa in areas neighboring gastric metaplasia.

Figure 2, designed by the Nobel Commission, shows the processes and stages of Helicobacter pylori infection leading to gastritis and both simple and complicated PU. It illustrates that infection is predominantly localized at the gastric antrum; chronic inflammation or gastritis, which is usually asymptomatic, increased gastric acidity, the resulting PU, and the latter's complications.

The association of Helicobacter pylori infection with the development of gastric carcinoma was demonstrated by epidemiological prevalence and case-control studies $(29,30)$. While only experimental data were missing, epidemiological observations were so clear that the World Health Organization classed Helicobacter pylori, in 1994, as a type-I cancerigenous agent (31). Subsequently a gastric carcinoma was developed in an experimental model using Helicobacter pylori-infected Mongolian gerbils (32).
Similarly, epidemiological studies showed that the prevalence of Helicobacter pylori infection was up to $100 \%$ in low-grade MALT gastric lymphomas (33). Based on these data an eradicating therapy was administered to patients with these tumors -gastric lymphomas histologically regressed following infection clearance, and then relapsed after reinfection with Helicobacter pylori (34).

These data completed the evolutionary possibilities of Helicobacter pylori-related gastritis, as well as its natural history since primary infection. Figure 3 summarizes the potential evolution of Helicobacter pylori in the gastric mucosa since primary infection. The earliest lesion is superficial gastritis, which may persist as such or become dinamically activated and progress to gastric mucosal atrophy. Intestinal tissue foci may develop in this stage -the so-called intestinal metaplasia. Cell injuries in these metaplastic areas may progress to dysplasia. The next stage is carcinomatous transformation. This evolutionary cycle occurs in just a few patients. Other environmental or dietary carcinogens supplement Helicobacter pylori activity. Causes influencing the development of gastric cancer in this small proportion of Helicobacter pylori-infected subjects are poorly understood. Potential genetic predisposing factors may play a pivotal role.

Another evolutionary line relates to DU and GU development. In the former case gastritis usually involves the antrum. Production capability for chlorhydric acid remains unchanged or even increases, which may also contribute to pathogenesis. Progression to lymphoma is possibly conditioned by the initial type of gastritis including lymphocytic infiltration in association with yet unknown genetic factors.

\section{MODIFICATIONS IN THE DIAGNOSIS AND THERAPY OF GASTROINTESTINAL DISORDERS}

The consistency of facts proving a relationship between Helicobacter pylori infection and gastritis, DU, $\mathrm{GU}$, gastric carcinoma, and gastric lymphoma warranted the use of new diagnostic and therapeutic modalities, which were very different to those employed that far, and were dubbed revolutionary.

Diagnostic methods were aimed at bacterial identification. Cultures had been achieved, and were highly specific but little sensitive. In addition they required gastric mucosal samples from endoscopic biopsy, and several days' incubation with technical difficulties; hence they were initially available in only a small number of microbiology laboratories.

Rapid urease testing takes advantage of urease contents in Helicobacter pylori to make gastric biopsies react with a solution containing urea and a marker. This method is fairly sensitive, specific, and cheap. It also re- 

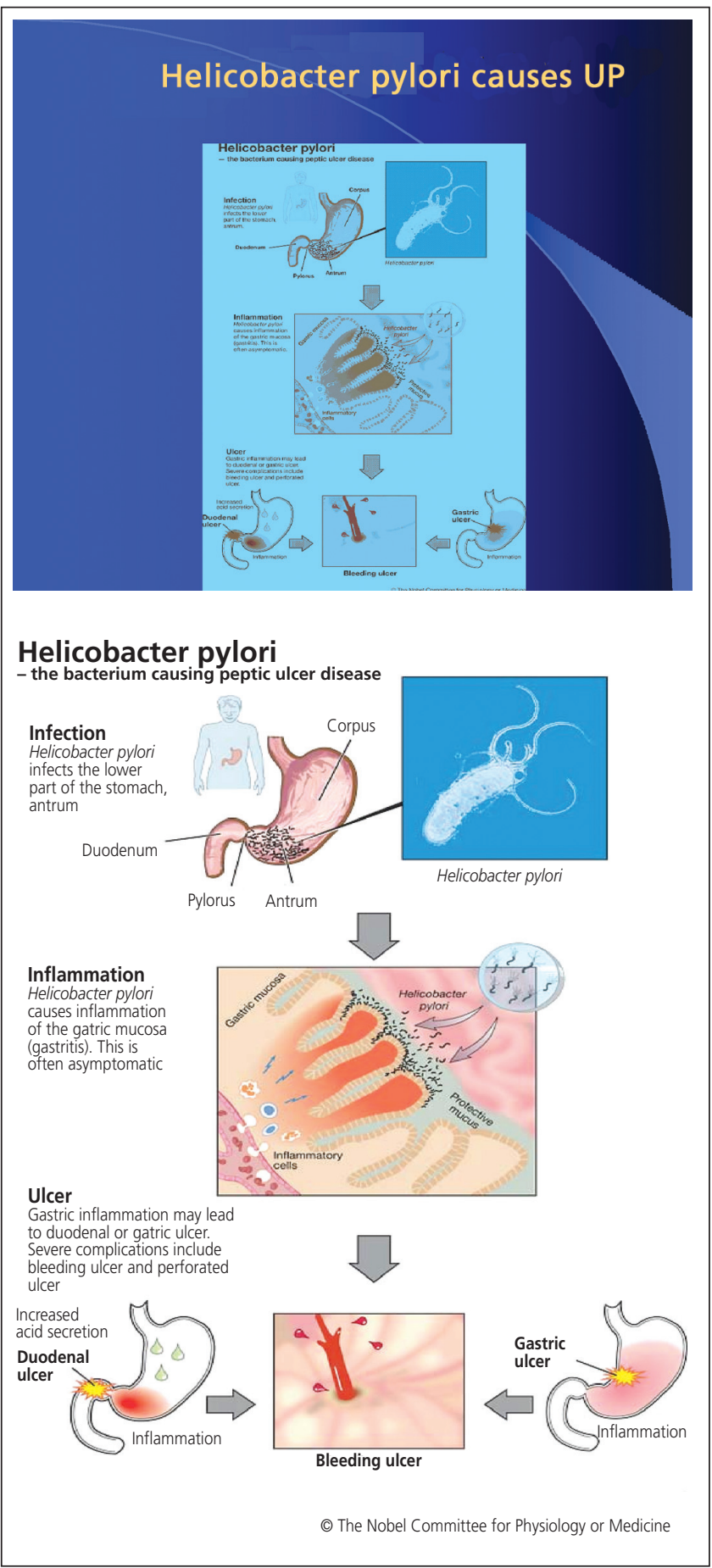

Fig. 2.- A diagram illustrating the pathogenetic mechanism of Helicobacter pylori infection.

Esquema del mecanismo patogénico de la infección por Helicobacter pylori.

quires endoscopy, as does histology using hematoxilineosin, Giemsa, and Warthin-Starry stains, as applied by Warren at bacterial discovery.

Research groups took advantage of Helicobacter pylori's capability to develop specific antibodies, and designed serology methods for its detection, some of them

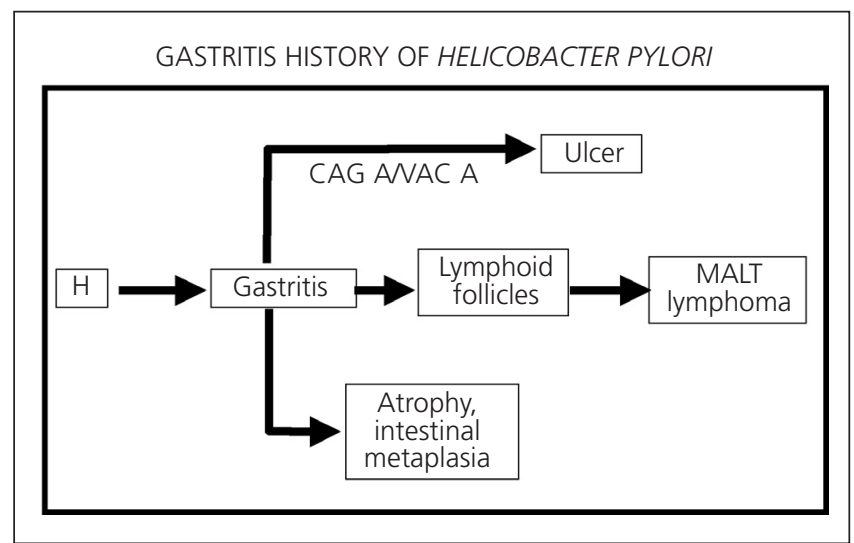

Fig. 3.- The natural history of Helicobacter pylori infection outlined. Esquema de la historia natural de la infección Helicobacter pylori.

qualitative in nature and very fast regarding performance. Other allowed a quantization of antibody rates, which theoretically pointed out their potential usefulness to check therapy response. However, the slow reduction or clearance of this response to said antibodies following eradication discouraged clinicians from using them to confirm Helicobacter pylori eradication after therapy in clinical practice. However, their high sensitivity and specificity, easy application to greater populations, and low cost turned serology into an ideal method for epidemiological studies.

The possibility to add a radionuclide to urea inspired a group of investigators, who managed to label urea using the radioactive, unstable $\mathrm{C}^{14}$, and the non-radioactive, stable $\mathrm{C}^{13}$ radionuclides. The radioactive method did not spread much because of its potential, yet minimum risks. Its use is not allowed in children and pregnant women. The method using the stable isotope $\mathrm{C}^{13}$ for labeling -designed by Graham and Klein in 1987, and designated urea breath test-is based on the reaction of urease in $\mathrm{He}$ licobacter pylori, active and present in the gastric mucosa, with an ingested solution containing $\mathrm{C}^{13}$-urea (35). Ureasa cleaves urea to liberate ammonia, water, and ${ }^{13} \mathrm{CO}_{2}$, which is expelled in expired air. With a number of methodological variations available to facilitate its use, this test is accepted by most patients because of easy performance, lack of adverse effects, excellent tolerability, and high sensitivity and specificity. The primary indication of this diagnostic modality is to verify Helicobacter pylori eradication.

Finally other tests, including fecal Helicobacter pylori antigen screening using polyclonal and monoclonal antibodies, complete diagnostic methods.

The management of PU has experienced a relevant change over time. The primary goal of PU therapy has evolved from neutralizing or reducing acid secretion to eradicating Helicobacter pylori infection. Modern therapeutic regimens combine potent antisecretory agents -proton-pump inhibitors (omeprazole, lansoprazole, pan- 
toprazole, rabeprazole, esomeprazole)- with two antimicrobial agents (amoxicillin and clarithromycin or a nitroimidazolic compound). Treatment duration (from 7 to 14 days) is controversial. This association cures around $80 \%$ of patients.

When infection fails to be eradicated, clarithromycin may be replaced by a nitroimidazolic compound (metronidazole, tinidazole) or vice versa. A quadruple regimen including a proton-pump inhibitor, bismuth, tetracycline, and metronidazole is usually recommended $(36,37)$.

\section{WHY WAS THE SCIENTIFIC COMMUNITY SO LATE IN ACCEPTING THE ROLE OF HELICOBACTER PYLORI?}

The answer to this question is not an easy one. Doubtless, the routine behavior driving daily clinical practice was a factor. Similarly, resistance to change, difficulties in rejecting official truth -"bacteria will not grow in an acidic medium"- prevented many a physician from accepting this discovery.

Other less personal, more reasonable factors doubtlessly favored skepticism and hesitancy within the medical community. Any biological discovery, particularly in relation to medicine regarding a disorder's etiology or therapy, demands support on substantial research, both basic and clinical. As regards Helicobacter pylori, basic science research was initially non-existent or highly limited. There was no animal model where inoculation could reproduce lesions seen in human stomachs, which made the proving of the pathogenetic hypothesis a difficult task, and hence early explanations were inadequate and scarcely believable.

Similarly, while early therapy managed to cure some cases, these were initially merely a few, and a high proportion of patients remained uncured. Furthermore, there was also a lack of interest, apathy, and on occasions a firm and planned rejection by some major pharmaceutical companies with a contrary interest regarding PU therapy (anti-infectious therapy precluded prolonged antisecretory agent regimens, which reduced sales).

However, a relevant minority of clinical, microbiological, immunological, pathological, and pharmacological investigators accepted the discovery from the start, attracted as they were by the finding's originality and immediate clinical implications. Many changes research fields or incorporated this topic into their activities, as the easily accessible and manipulable human stomach facilitated the performance of predesigned experiments. Some clinicians immediately started to treat their patients with ulcer with worrying distrust but also with hope and enthusiasm, which increased on acknowledging treatment efficacy and patient satisfaction.

The persuasion of "non-believers", of those refractory to changing their clinical habits, was a slow, difficult process during the early years as a result of scant financial funding for investigation and the reporting of data obtained. However, it was the tenacity of "believers", of those convinced that brought about change.

National and international work teams were set up. In Europe several researchers from European Union countries met in an informal conference that was held in Copenhaguen, in 1997, to share information on this subject, which gave rise to the European Helicobacter pylori Study Group. This group had the objective of promoting knowledge on diagnostic techniques, and on clinical and basic investigation methods, and above all the mission of facilitating and spreading information to physicians in European countries.

With a scarcity of means, counting on European Group members' personal efforts, and with the modest help from Gift-Brocades, a small Dutch pharmaceutical company, 1988 saw the first multidisciplinary workshop, attended by reseachers in all areas related to Campylobacter-Helicobacter from most European nations and other continents, particularly Australia and the USA.

Encouraged by success congresses were held in various European cities: Ulm, Toledo, Bologna, etc.; audiences were increasingly higher, with a maximum of 2,400 at the Lisbon meeting in 1997. In the last meeting of the European Group, held in Copenhagen, participation was also particularly high, but lower mainly due to a lesser attendance by clinicians.

In 1994, the US Health Institutes organized a debate on Helicobacter pylori infection, and prepared a consensus document that served American physicians as guidelines for their practice regarding patients with ulcer. A meeting for clinicians and investigators experienced in Helicobacter pylori was held, so that they would debate on the subject and ultimately agree on diagnostic and therapeutic schemes. They reached a minimum agreement that solely included therapy for simple relapsing PU, which was reported in a document published in JAMA that same year (38). Two years later the European Group, in their Maastricht meeting, agreed on wider indications for Helicobacter pylori eradicating therapy: simple and complicated PU, gastritis, lymphoma, dyspepsia, and "in situ" gastric carcinoma, even if scientific evidence grades varied. Similarly a triple eradicating regimen was recommended for one week rather than 14 days, as well as a quadruple regimen made up of proton-pump inhibitor, bismuth, tetracycline, and metronidazole (39). More recently the second edition of the European guidelines for Helicobacter pylori infection was published (40). As a result of these publications all recommended therapy regimens and diagnostic indications were fully accepted worldwide.

Physicians and other investigators in Japan and other Asian countries united efforts. In 1995, a Japanese Society for the investigation of Helicobacter pylori infection and associated gastroduodenal disorders is founded. Joint projects arise to promote investigation and cooperation in 
information spreading. One year later Graham published the first journal on this bacterium -"Helicobacter".

Several practical courses on methodology were subsequently held in Bordeaux, and Galway. In Spain, Sigüenza was the venue for a course on clinical trials regarding Helicobacter pylori infection. In 1997, the European Group organized a workshop to design guidelines for clinical trial protocolization. Their conclusions were published that same year (41).

\section{IS THERE A FUTURE FOR RESEARCH ON HELICOBACTER PYLORI?}

Even if the interest of investigators for Helicobacter pylori infection has decreased, numerous problems remain that need a solution, numerous questions persist that require an answer. The field is extensive enough to still excite active researchers. It still has features that may thrill young investigators into a research line on this topic.

Some data that may be an object for reflection will be tentatively discussed.

More than 2,000 million infected people are currently alive worldwide; this entails an enormous potential for expansion, since person-to-person transmission is the preferential propagation mechanism. Poorly developed countries with healthcare deficiencies have an infection prevalence greater than $80 \%$, which involves a high rate of gastritis, PU, and gastric carcinoma. Gastric carcinoma is the first cause of mortality in many countries.

The development of antimicrobial resistance in Helicobacter pylori increases with antibiotic use. As a consequence, it is urgent that microbiologists investigate resistance mechanisms, and that pharmacologists discover new genoma- and proteoma-based drugs that are effective in the treatment of resistant strains.

While investigations to develop a preventive vaccine started years ago, none has been achieved yet. Obtaining a preventive and curative vaccine, and its potential widespread use in countries with high infection rates, still represents a serious challenge.

Investigation directed to unveil the pathogenetic mechanisms of inflammatory lesions from Helicobacter pylori infection at the gastroduodenal mucosa has contributed to a better understanding of the human immune response. This has sparked interest in basic science researchers to analyze and understand immune reactions at the digestive mucosa when colonized and infected by other bacteria. It also inspired projects for experiments to elucidate the function of the intestinal flora, and its relation to immune response in the gastrointestinal mucosa.

A particularly interesting area is the relationship between Helicobacter pylori infection and extradigestive disorders. This is an area with inconclusive data that is plagued with questions still awaiting response and highly relevant for clinical practice.

\section{ACKNOWLEDGEMENTS}

This review was partly supported by two grants from Instituto de Salud Carlos III (C03/02 y PI050109).

\section{REFERENCES}

1. Press Release. The 2005 Nobel Prize in Physiology or Medicine. 3rd October 2005. Available at: http://www.nobelprize.org

2. Warren JR. The discovery of Helicobacter pylori in Perth, Western Australia. In: Marshall B, editor. Helicobacter Pioneers (Firsthand account from the scientists who discovered helicobacters. 1892-1982). Blackwell Science Asia; 2002. p. 151-64.

3. Allen Pin. What's the story H. pylori? (Feature). Lancet 2001; 1: 694.

4. Fung WP, Papadimitriu JM, Matz LR. Endoscopic, histological and ultrastructural correlations in chronic gastritis. Am J Gastroenterol 1979; 71: 269-79.

5. Marshall BJ. The discovery that Helicobacter pylori, a spiral bacterium, caused peptic ulcer disease. In: Marshall B, editor. Helicobacter Pioneers (Firsthand account from the scientists who discovered helicobacters. 1892-1982). Blackwell Science Asia; 2002. p. 165-202.

6. Martin DF, Hollanders D, May SJ, Ravenscroft MM, Tweedle DE, Miller JP. Differences in relapse rates of duodenal ulcer after healing with cimetidine or tripotassium dicitrato bismuthate. Lancet 1981; 1: 7-10.

7. Gregory MA, Moshal MG, Spitaels JM. The effect of tri-potassium di-citrato bismuthate on the duodenal mucosa during ulceration. An ultrastructural study. S Afr Med J 1982; 62: 52-5.

8. Marshall BJ, Warren JR. Unidentified curved bacilli in the stomach of patients with gastritis and peptic ulceration. Lancet 1984; 1: 1311-5.

9. McNulty CA, Watson DM. Spiral bacteria of the gastric antrum. Lancet 1984; 1: 1068-9.

10. Langenberg W, Tytgat GN, Shipper ME, et al. Campylobacter-like organism in the stomach of patients and healthy individuals. Lancet 1984; 1: 1348-9.

11. Eldridge J, Lessels AM, Jones DM. Antibody to spiral organisms on gastric mucosa. Lancet 1984; 1: 1237.

12. Marshall BJ, Armstrong JA, McGechie DB, Glancy RJ. Attempt to fulfill Koch's postulates for pyloric Campylobacter. Med J Aust 1985; 142: 436-9.

13. Warren JR. Unidentified curved bacilli on gastric epithelium in active chronic gastritis. Lancet 1983; 1: 1273.

14. Marshall B. Unidentified curved bacilli on gastric epithelium in active chronic gastritis. Lancet 1983; 1: 1273-4.

15. Jones DM, Curry A, Fox AJ. An ultrastructural study of the gastric Campylobacter-like organism "Campylobacter pyloridis". J Gen Microbiol 1985; 131: 2335-41.

16. Davis CP, Cleven D, Brown J, et al. Anaerobiospirillum, a new genus of spiral-shaped bacteria. Int J Syst Bacteriol 1976; 26: 498-504.

17. Beji A, Megraud F, Vincent P, Gavini F, Izard D, Leclerc H. GC content of DNA of Campylobacter pylori and other species belonging to the genus Campylobacter. Ann Inst Pasateur/Microbiol 1988; 138: 527-34.

18. Thompson LM, Smibert RM, Johnson JL, et al. Phylogenic study of the genus Campylobacter. In J Syst Bact 1988; 38: 109-200.

19. Lambert MA, Patton CM, Barrett TJ, Moss CW. Differentiation of Campylobacter and Campylobacter-like organisms by cellular fatty acid composition. J Clin Microbiol 1987; 25: 706-13.

20. Hazell SL. Microbiology and taxonomy of Helicobacter pylori and related bacteria. In: Marshall BJ, McCallum R, Guerrant RL, editors. Helicobacter pylori in peptic ulceration and gastritis. Boston: Blackwell Scientific Publications; 1991. p. 19-34.

21. Goodwin CS, Armstrong JA, Chilvers T, et al. Transfer of Campylobacter pylori and Campylobacter mustelae to Helicobacter gen.nov.as Helicobacter pylori comb.nov. and Helicobacter mustelae comb.nov., respectively. Int J Syst Bacteriol 1989; 39: 397-405.

22. Johnston BJ, Reed PI, Ali MH. Campylobacter-like organisms in duo- 
denal and antral endoscopic biopsies: Relationship to inflammation. Gut 1986; 27 : 1132-7.

23. Jiang SJ, Liu WZ, Zhang DZ, Shi Y, Xiao SD, Zhang ZH, et al. Campylobacter-like organisms in chronic gastritis, peptic ulcer, and gastric carcinoma. Scand J Gastroentrol 1987; 22: 553-8.

24. Coghlan JG, Gilligan D, Humphries H, McKenna D, Dooley C, Sweeney E, et al. Campylobacter pylori and recurrence of duodenal ulcers -a 12 month follow-up study. Lancet 1987; 2: 1109-10.

25. Raws EAJ, Tytgat GNJ. Cure of duodenal ulcer associated with eradication of H. pylori. Lancet 1990; 335: 1233.

26. Wyatt JI, Rathbone BJ, Dixon MF, Haetley RV. Campylobacter pyloridis and acid-induced gastric metaplasia in the pathogenesis of duodenitis. J Clin Pathol 1987; 40: 841-8.

27. Crabtree JE, Shallcross TM, Heatley RV, Wyatt JI. Mucosal tumor necrosis factor alpha and interleukin-6- in patients with Helicobacter pylori associated gastritis. Gut 1991; 32: 1473-7.

28. Moss SF, Legon S, Bishop AE, Plak JM, Calam J. Effect of Helicobacter pylori on gastric somatostatin in duodenal ulcer disease. Lancet 1992; 340: 930-2.

29. Parsonnet J, Friedman GD, Vandersteen DP, Chang Y, Vogelman JH, Orentreich N, et al. Helicobacter pylori infection and the risk of gastric carcinoma. New Eng J Med 1991; 325: 1127-31.

30. Nomura A, Stemmermann GN, Chyou PH, Kato I, Pérez-Pérez GI, Blaser MJ. Helicobacter pylori infection and gastric carcinoma among Japonese Americans in Hawaii. New Eng J Med 1991; 325: 1132-6.

31. IARC. Monographs on the evaluation of the Carcinogenic risks to human. Vol. 61. Schistosomes, liver flukes and Helicobacter pylori. Lyon: International Agency for Research on Cancer; 1994.

32. Watanabe T, Tada M, Nagai H, Sasaki S, Nakao M. Helicobacter pylori induces gastric cancer in monogolian gerbils. Gastroenterology 1998; 115: 642-8.

33. Wotherspoon AC, Ortiz-Hidalgo C, Falzon MR, Isaacson PG. Helicobacter pylori-associated gastritis and primary B-cell gastric lympho- ma. Lancet 1991; 338: 1175-6

34. Wotherspoon AC, Doglioni C, Diss TC, Pan L, Moschini A, de Boni $\mathrm{M}$, et al. Regression of primary low-grade B cell lymphoma of mucosa associated lymphoid tissue type after eradication of Helicobacter pylori. Lancet 1993; 342: 575-7.

35. Graham DY, Klein PD, Evans DJ Jr, Evans DG, Alpert DC, Opekun $\mathrm{AR}$, et al. Campylobacter pylori detected non-invasively by the 13Curea breath test. Lancet 1987; 1: 1174-7.

36. Monés J, Gisbert JP, Bordá F, Domínguez Muñoz E y "Grupo Conferencia Española de Consenso". Indications, diagnostic methods, and eradication treatment of Helicobacter pylori. Recommendations of the second Spanish Consensus Conference. Rev Esp Enferm Dig 2005; 97: 348-74.

37. Gisbert JP, Calvet X, Gomollón F, Monés J y "Grupo Conferencia Española de Consenso sobre Helicobacter pylori". Tratamiento erradicador de Helicobacter pylori. Recomendaciones de la II Conferencia Española de consenso. Med Clin (Barc) 2005; 125: 301-16.

38. NIH Consensus Conference. Helicobacter pylori in peptic ulcer disease: NIH Consensus Development Panel on Helicobacter pylori in Peptic Ulcer Disease. JAMA 1994; 272: 65-9.

39. European Helicobacter pylori Study Group. Current European concepts in the management of Helicobacter pylori infection. The Maastricht Consensus Report. Gut 1997; 41: 8-13.

40. Malfertheiner P, Megraud F, O'Morain C, Hungin AP, Jones R, Axon $\mathrm{A}$, et al. Current concepts in the management of Helicobacter pylori infection - The Maastricht 2-2000 Consensus Report. Aliment Pharmacol Ther 2002; 16: 167-80.

41. Working Party of the European Helicobacter pylori Study Group. Guidelines for clinical trials in H. pylori infection. Gut 1997; 41 (Supl. 2): S1-9. 